Article

\title{
The Effect of Core Stabilization Exercise with the Abdominal Drawing-in Maneuver Technique on Stature Change during Prolonged Sitting in Sedentary Workers with Chronic Low Back Pain
}

\author{
Pongsatorn Saiklang ${ }^{1}$, Rungthip Puntumetakul ${ }^{2,3, *(\mathbb{D})}$ and Thiwaphon Chatprem ${ }^{2}$ \\ 1 Division of Physical Therapy, Faculty of Physical Therapy, Srinakharinwiroj University, \\ Nakhonnayok 26120, Thailand; Pongsatornsa@g.swu.ac.th \\ 2 Research Center of Back, Neck, Other Joint Pain and Human Performance (BNOJPH), Khon Kaen University, \\ Khon Kaen 40002, Thailand; Thiwaphon.ao@gmail.com \\ 3 Department of Physical Therapy, Faculty of Associated Medical Sciences, Khon Kaen University, \\ Khon Kaen 40002, Thailand \\ * Correspondence: Rungthiprt@gmail.com
}

check for updates

Citation: Saiklang, P.; Puntumetakul, R.; Chatprem, T. The Effect of Core Stabilization Exercise with the Abdominal Drawing-in Maneuver Technique on Stature Change during Prolonged Sitting in Sedentary Workers with Chronic Low Back Pain. Int. J. Environ. Res. Public Health 2022, 19, 1904. https://doi.org/10.3390/ ijerph19031904

Academic Editors: Sergio Iavicoli, Vincenzo Denaro, Gianluca Vadalà and Fabrizio Russo

Received: 23 December 2021

Accepted: 5 February 2022

Published: 8 February 2022

Publisher's Note: MDPI stays neutral with regard to jurisdictional claims in published maps and institutional affiliations.

Copyright: (C) 2022 by the authors. Licensee MDPI, Basel, Switzerland. This article is an open access article distributed under the terms and conditions of the Creative Commons Attribution (CC BY) license (https:// creativecommons.org/licenses/by/ $4.0 /)$.

\begin{abstract}
To enhance stature recovery, lumbar spine stabilization by stimulating the deep trunk muscle activation for compensation forces originating from the upper body was introduced. The abdominal drawing-in maneuver (ADIM) technique has been found mainly to activate deep trunk muscles. The purpose of the current study was to determine whether 5 weeks of training of deep trunk muscles using the ADIM technique could improve stature recovery, delay trunk muscle fatigue, and decrease pain intensity during prolonged sitting. Thirty participants with chronic low back pain (CLBP) conducted a core stabilization exercise (CSE) with the ADIM technique for 5 weeks. Participants were required to sit for $41 \mathrm{~min}$ before and after the exercise intervention. Stature change was measured using a seated stadiometer with a resolution of $\pm 0.006 \mathrm{~mm}$. During sitting, the stature change, pain intensity, and trunk muscle fatigue were recorded. A comparison between measurements at baseline and after 5 weeks of training demonstrated: (i) stature recovery and pain intensity significantly improved throughout the $41 \mathrm{~min}$ sitting condition; (ii) the bilaterally trunk muscle showed significantly decreased fatigue. The CSE with the ADIM technique was shown to provide a protective effect on detrimental reductions in stature change and trunk muscle fatigue during prolonged sitting in young participants under controlled conditions in a laboratory. This information may help to prevent the risk of LBP from prolonged sitting activities in real life situations.
\end{abstract}

Keywords: spinal load; core stability; ergonomics

\section{Introduction}

Sedentary behavior is characterized by an energy expenditure less than or equal to 1.5 metabolic equivalents (METs) while in a sitting or reclining position when awake [1]. Today, increasing numbers of individuals spend extended periods in a seated position at work as well as during leisure time [2,3]. Recently, sedentary workers in Thailand reported recurring low back pain, with $63 \%$ showing that their low back pain was aggravated by sitting during working hours [4]. Chronic low back pain (CLBP) has a global prevalence of $11-23 \%$ among people with low back pain $[5,6]$. The socioeconomic burden of CLBP stems from a prolonged loss of function, which consequently results in decreased work productivity and increased medical costs [5,7].

Deep trunk muscle fatigue may arise from continuous contraction of the trunk muscles during prolonged sitting [8-10]. This fatigue reduces muscular support to the spine and increases stress on ligaments and intervertebral discs [9,10]; consequently, it reduces intervertebral disc height [11,12]. Reductions in disc height could increase compressive 
stress on sensitive spinal structures $[13,14]$ and may stimulate nociceptor activity, leading to pain [14]. Stature change measurement is a method used to reflect alterations in spinal length, and the reduction of spinal length is known as spinal shrinkage or stature loss [15]. Prolonged sitting postures could lead to stature reduction and ultimately to low back pain $[9,16,17]$.

Trunk muscles play an essential role in contributing to spinal stability [18]. There are two types of trunk muscle systems: superficial and deep [19,20]. The internal oblique (IO), transversus abdominis (TrA), and lumbar multifidus (LM) muscles represent a deep muscle system that compensates for forces on the upper body of the spine and increases lumbar stability $[18,21]$. Previous studies reported changes in the muscle recruitment pattern and timing of muscle onset in people with low back pain [22,23]. Increased superficial trunk muscle activation occurs to compensate for deep trunk muscle dysfunction [24,25], in which the neural control subsystem attempts to maintain spinal stability $[18,26]$. Increased activation of the superficial trunk muscle can compress the spinal structure and lead to delayed stature recovery $[25,27]$.

Previous research reported that superficial trunk muscle activity can be reduced by activating the deep trunk muscles using the abdominal drawing-in maneuver (ADIM) technique $[15,28,29]$. The ADIM technique is known to elicit preferential recruitment of the transversus abdominis muscle with minimal activation of the superficial trunk muscles. For this technique, participants are instructed to 'gently draw in their lower abdomen toward the spine' [13]. Saiklang et al. (2020) investigated the change in stature recovery in patients with CLBP following the immediate effect of the ADIM technique for $1 \mathrm{~min}$ repeated three times throughout a 41 min prolonged sitting period. The results demonstrated that the ADIM technique significantly improved stature recovery and increased TrA and IO muscle activities and $\operatorname{Tr} \mathrm{A}$ and IO/RA ratios compared with upright sitting without exercise [15].

To date, no investigation has reported the effect of the long-term impact of the core stabilization exercise (CSE) with the ADIM technique program focusing on deep trunk muscle on stature recovery during prolonged sitting. The CSE with ADIM technique aims to improve neuromuscular control skills, relearn normal function, and enhance endurance of the deep muscles around the lumbar spine, such as the TrA and LM muscles [28,30].

The aim of the current study was to investigate differences in stature change, pain, and trunk muscle fatigue during prolonged sitting in seated sedentary workers with CLBP between baseline and the first day after a 5-week CSE with the ADIM technique. We hypothesized that the 5-week CSE with the ADIM technique can improve deep trunk muscle endurance, reduce pain, and delay stature reduction during prolonged sitting.

\section{Materials and Methods}

\subsection{Design and Setting}

The study used a within-subject repeated-measures design. It was conducted at the research center of the Back, Neck, Other Joint Pain and Human Performance (BNOJPH) laboratory, Khon Kaen University, Thailand. Ethics approval for this research was granted before the study by the Human Research Ethics Committee (HE612220) of Khon Kaen University. The study was registered at clinicaltrials.in.th (registration number: TCTR20180823004).

\subsection{Participants}

Thirty participants, aged 20-39 years, were recruited via posters on bulletin boards at Khon Kaen University. Fifteen males and fifteen females were recruited to reduce the influence of gender. Inclusion criteria for the participants were established as follows: CLBP lasting more than three months, mild to moderate levels of pain on the numerical rating scale (NRS; $\leq 7$ score) [31,32], low levels of activity limitation on the Roland Morris disability questionnaire (RMDQ; $\leq 12$ score) [33], and reported sitting for at least two hours on any working day [9]. Participants were excluded if they had previous vertebral surgery, 
had been identified with a medical condition that affected spinal soft tissues, or were pregnant [32,34].

\subsection{Sample Size Determination}

The sample size was calculated after preliminary data collection from 12 participants (six male and six female) who performed the CSE with ADIM for 5 weeks. The mean difference of the stature changes before and after the exercise intervention was set at $3 \mathrm{~mm}$. A significance level of $0.05(Z \alpha(0.05)=1.96)$ and a power of $90 \%(Z \beta(0.1)=1.28)$ were used in the calculation. After an additional 15\% correction for dropouts, the number of subjects was 21 . Thus, the current study required at least 30 participants (15 males and 15 females for balanced gender) to achieve sufficient statistical power for the analyses.

\subsection{Outcome Measurements}

\subsubsection{Stature Change Response}

Stature change response was measured using a seated stadiometer device (certified Thai petty-patent No. 5607; Figure 1) [15,34]. The Digimatic Indicator identifies variations in stature change with a resolution of $\pm 0.006 \mathrm{~mm}$ and was used to measure stature change. The device displays real-time data and repeatedly records data up to $5 \mathrm{~Hz}$ (ID-C 150, 1050 Digimatic Indicator, Manual No. 3061, Series No. 543, Mitutoyo, Kawasaki, Japan).

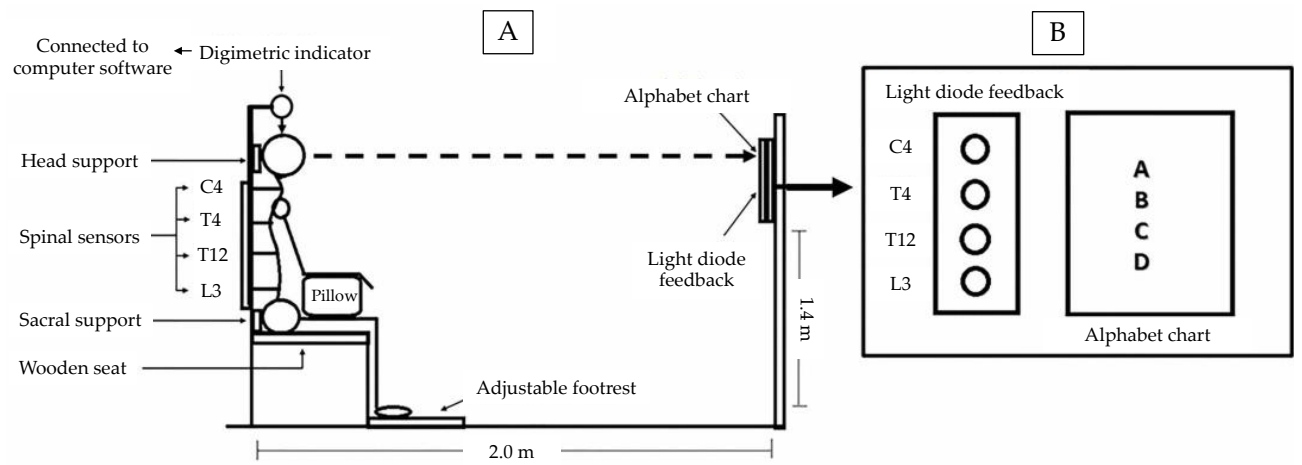

Figure 1. A seated stadiometer device: (A) participant position, (B) feedback chart. Source: [15].

The position of the participants was controlled during the measurements as follows:

(i) The Digimatic Indicator settings allowed the distal end to rest directly on the highest apex of the skull to ensure its consistent positioning throughout participant repositioning (Figure 1) [15,34].

(ii) Head positioning with the eyes kept level was maintained by coaching the participants to concentrate on a visual cue, a letter on an alphabet chart, placed at eye level on the opposite end (Figure 1B) [15,34].

(iii) The wooden seat platform and footrest were adjustable so that the participants' ankle, knee, and hip joints were positioned at $90^{\circ}$ throughout the measurements. Heels touched the back of the footrest [35]. The head and sacral supports were adjustable to accommodate the participants' spinal posture [35]. A pillow was placed on the participants' lap to support their forearms positioned at $90^{\circ}$ to their upper arms (Figure 1A).

(iv) The spinal alignment was controlled by sensors placed on the spinous processes of the following vertebrae: cervical spine 4, thoracic spine 4, thoracic spine 12, and lumbar spine 3. These sensors were connected to a light diode feedback located opposite the seated participant (Figure 1B) [12,15]. These sensors were used as a measure for control to ensure that the participants maintained the same posture throughout the experiment period. The process of stature change measurement was performed by Researcher P.S.

\subsubsection{Trunk Muscle Fatigue}

Eight pairs of $\mathrm{Ag}-\mathrm{AgCl}$ disposable surface electromyography (sEMG) electrodes (EL 503) with electrical contact surface areas of $1 \mathrm{~cm}^{2}$ and a center-to-center spacing of $2.5 \mathrm{~cm}$ 
were attached parallel to each muscle on both sides: to the rectus abdominis muscle (RA) [36], the internal oblique and transversus abdominis ( $\mathrm{IO}$ and $\operatorname{Tr} \mathrm{A}$ ) [37], the iliocostalis lumborum pars thoracis (ICLT) [38], and the lumbar multifidus (LM) [30] after skin abrasion and cleaning with alcohol. Electromyography (EMG) data were recorded at $2000 \mathrm{~Hz}$ using the Wireless Bipolar Cometa Mini Wave Plus 16-channel EMG system (Cometa, Bareggio, Italy), an online band-pass filter $(10-500 \mathrm{~Hz})$, and a $60 \mathrm{~Hz}$ notch filter (power line in Thailand). The raw EMG signal was first visually checked for electrocardiac artifacts. The raw EMG signal was processed with fast Fourier transformation to determine the median frequency $(\mathrm{MDF})$ value $(\mathrm{Hz})$. The decrease in the MDF of the EMG signal was taken as an indirect measure of muscle fatigue [6]. Trunk muscle fatigue was collected by Researcher P.S.

\subsubsection{Pain Rating Scale}

Pain intensity was assessed using an 11-point numerical rating scale (0-10 NRS). Subjective measures of pain were obtained from the NRS, employed to assess pain on a scale ranging from 0 (no pain) to 10 (worst possible pain) [31,39]. This outcome measurement was evaluated by Researcher T.C.

\subsubsection{Functional Disability}

The Roland Morris disability questionnaire (RMDQ) Thai version was used to assess functional disability due to low back pain [40]. This questionnaire includes 24 items [41], which were rated by Researcher T.C.

\subsection{Procedure}

The flowchart of the current study is presented in Figure 2. Thirty-three participants were recruited from the advertisements. After the screening process, 30 participants were included in the study. Three participants were excluded due to experiencing low back pain $>7$ based on the NRS. Thirty participants meeting the inclusion criteria were asked to visit the research laboratory.

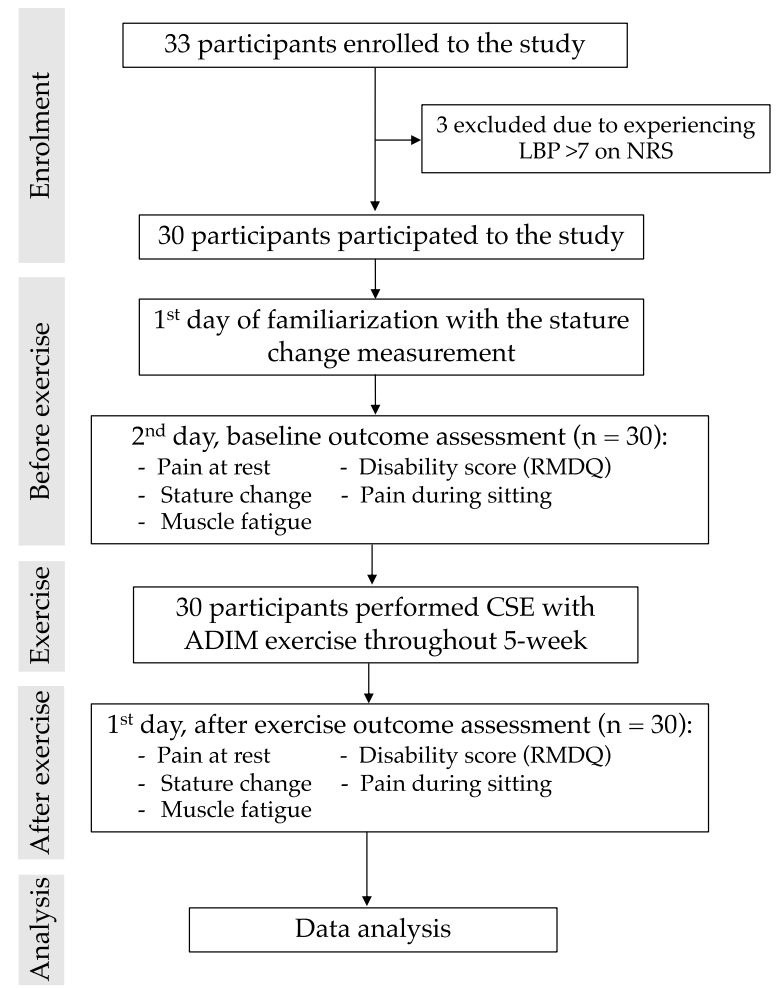

Figure 2. Flowchart of the study. 
On the first day, the participants were familiarized with the stature change measurement. These involved participants practiced stepping in and out of the stadiometer until a standard deviation (SD) of $<0.5 \mathrm{~mm}$ was achieved over ten repeated stature measurements $[12,42]$. Then, they were asked about their disability score (RMDQ) and pain intensity at rest (NRS).

On the second day, all participants arrived within an hour of waking, between 8 and 10 a.m. $[42,43]$ to avoid stature loss before the test trial. They were requested to sleep for at least $8 \mathrm{~h}$ each night before the days of the experiment [44]. They were asked to undertake normal activities of daily living, refrain from vigorous physical activities, and refrain from alcohol consumption for $24 \mathrm{~h}$ before the experimental sessions [45]. After the application of surface electrodes, the participants were asked to maintain the Fowler's position (lying) for 20 min to eliminate any abnormal spinal loading that may have been present before arrival $[34,45]$. Then, they were asked to sit for $41 \mathrm{~min}$, and the outcome measurements were collected, as shown in Figure 3.

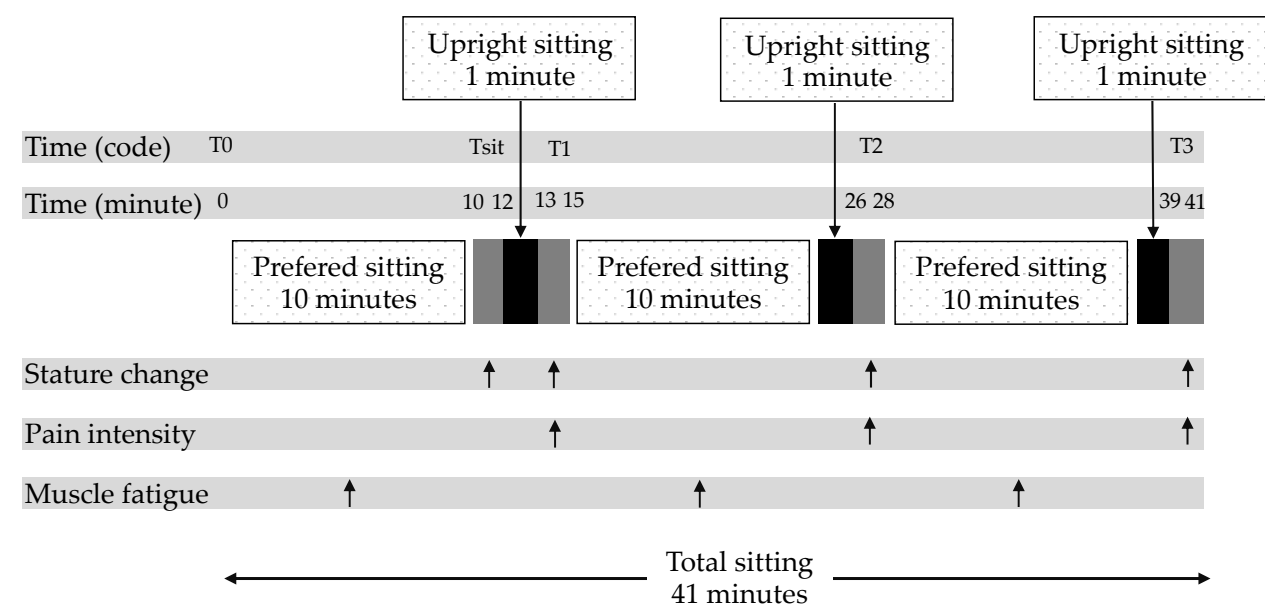

Figure 3. Overview of the prolonged sitting condition. The upright sitting periods (back zone) are presented below the axis. Arrows illustrate times of outcome measurement: stature change, pain intensity, and muscle fatigue. Participants sit in the seated stadiometer and perform the upright sitting three times (at 12-13, 25-26, and 38-39 $\mathrm{min}$ ) throughout the prolonged sitting time of $41 \mathrm{~min}$. Stature change measurements are collected at Tsit (10-12 min), T1 (13-15 min), T2 (26-28 min), T3 (39-41 min). Pain intensity measurements are collected at T1 (13-15 min), T2 (26-28 min), and T3 (39-41 min). Muscle fatigue measurements are collected at 0-10, 15-25, and 28-38 min.

Next, the participants were asked to practice CSE using the ADIM technique with the researcher R.P. When they could perform this correctly, they were required to exercise CSE with ADIM for 5 weeks. After 5 weeks of training, all participants were asked to stop their exercises completely. The outcomes were re-measured on the first day after the 5-week CSE with the ADIM technique.

\subsection{Prolonged Sitting Condition}

An overview of the prolonged sitting condition, with time points and their outcome measurements, is shown in Figure 3. Participants sat in the seated stadiometer, according to conditions described in 2.4.1, with the Digimatic Indicator in contact with the skull apex, marked by a waterproof pen. During the measurements, the participants remained in the same posture without speaking. To reduce errors in the spinal change measurements due to involuntary movements and slight differences in the breathing phase, all measurements were taken at the end of the expiration phase of the breathing cycle [35,46]. Each measurement set, consisting of 75 data points sampled over $15 \mathrm{~s}$, was considered at time 0 and at the end of a 2 min interval, which reduced the effect of variations in the stature change assessment due to both breathing patterns and uncontrolled movements [12,34,35]. 
A baseline stature measurement set was recorded $\left(\mathrm{T}_{0}\right)$. During the test trials, the participants remained in a freestyle sitting position, which did not require a straight back, without a backrest for $10 \mathrm{~min}$. Then, the stature change (Tsit) in the participants was measured to be used as a normalized value. Next, the participant was asked to sit upright for $1 \mathrm{~min}$. The stature change and pain intensity were measured at the end of each session (T1 [at 13-15 min], T2 [at 26-28 min], and T3 [at 39-41 min]). The raw sEMG signal was processed using the triangle-Bartlett method of fast Fourier transformation to determine the median frequency (MDF) value. The sEMG data were retrieved every 10 min block of sEMG data from the 41 min sitting period (at 0-10, 15-25, and 28-38 min) for analysis, Figure 3. The total time for each test trial was $41 \mathrm{~min}$. Participants were not allowed to stand during the test trials.

\subsection{Core Stabilization Exercise (CSE) with ADIM Technique}

The exercise program was supervised by a physical therapist with 30 years of experience (RP). This exercise program was modified from Puntumetakul et al. [28]. The details of the CSE each week are appended (Table A1). Researcher R.P. trained this exercise to all participants face-to-face in a 20 min session. The participants were re-assessed with researcher R.P. twice a week for 5 weeks at the laboratory to determine whether they could successfully perform the previous exercise. As the CSE with the ADIM technique was a milestone exercise, if the participants failed to perform the previous exercise accurately, they were retrained in the previous exercise until they succeeded. The participants were required to perform a daily set of home exercises of the same level, position, and frequency as those demonstrated during the exercise session with the physical therapist. The participants were asked to record in their logbook a daily home exercise program, including position, duration, and frequency of the exercise, as well as a record of their drug and alternative treatment throughout the study period and any adverse effects of the exercise. During the exercise, one of the researchers contacted the participants by telephone every week to motivate them to continue their daily home exercises. After 5 weeks of training, all participants were asked to stop their exercises completely.

\subsection{Data Analysis}

The mean and standard deviation (SD) were used to assess participants' demographics and data of stature change at each time of measurement and were calculated from the reference point of $\mathrm{T}_{\text {sit }}$. Differences in stature within a condition were assessed using a one-way repeated measure ANOVA for time effect $\left(T_{1}, T_{2}\right.$, and $\left.T_{3}\right)$ with the Bonferroni post-hoc analysis (significant at $p<0.017 ; 0.05 / 3$ ).

The differences in trunk muscle fatigue and pain intensity within the condition for non-normally distributed data were analyzed using the Friedman test, and post hoc tests were conducted using Wilcoxon signed-rank tests. A significance level was set at $p<0.05$ for trunk muscle fatigue and pain intensity.

Data comparisons before and after the first day of the 5-week CSE regarding pain at rest and functional disability were analyzed using the paired $t$-test $(p<0.05)$. During the prolonged sitting condition, the data comparison before and after the first day of 5 weeks of the exercise on stature change was analyzed using the paired $t$-test $(p<0.05)$. Further, the pain intensity and trunk muscle fatigue were analyzed using Wilcoxon signed-rank tests $(p<0.05)$.

All analyses were performed using SPSS version 19.0 software (SPSS Inc., Chicago, IL, USA). The Shapiro-Wilk test was performed to check the data distribution.

\section{Results}

\subsection{Participant Characteristics}

All participants achieved the preferred level of repeatability for the stature change measurements ( $\mathrm{SD} \leq 0.5 \mathrm{~mm}$ ). The participants reported that they did not use any drug for reducing their low back pain and had no adverse repercussions of the exercise throughout 
the 5 weeks of the training. The demographic data and clinical characteristics are presented in Table 1.

Table 1. Demographic characteristics of participants.

\begin{tabular}{|c|c|c|c|}
\hline Characteristics & Male $(n=15)$ & Female $(n=15)$ & Total $(n=30)$ \\
\hline Age (years), mean \pm SD & $25.67 \pm 3.35$ & $26.07 \pm 3.37$ & $25.87 \pm 3.31$ \\
\hline Weight $(\mathrm{kg})$, mean $\pm \mathrm{SD}$ & $63.93 \pm 7.94$ & $52.80 \pm 4.84$ & $58.37 \pm 8.59$ \\
\hline $\mathrm{BMI}\left(\mathrm{kg} \mathrm{m}^{-2}\right)$, mean $\pm \mathrm{SD}$ & $22.11 \pm 1.90$ & $20.95 \pm 1.28$ & $21.53 \pm 1.70$ \\
\hline Sitting height $(\mathrm{cm})$, mean \pm SD & $87.93 \pm 5.38$ & $84.50 \pm 3.39$ & $86.22 \pm 4.75$ \\
\hline Standing height $(\mathrm{cm})$, mean $\pm \mathrm{SD}$ & $169.80 \pm 5.16$ & $158.67 \pm 4.70$ & $164.23 \pm 7.45$ \\
\hline Smoking status & no & no & no \\
\hline \multicolumn{4}{|l|}{ Occupation, n (\%) } \\
\hline -Student & $12(80)$ & $13(86.67)$ & $25(83.33)$ \\
\hline -Office worker & $3(20)$ & $2(13.33)$ & $5(16.67)$ \\
\hline Working time (hours/day), mean \pm SD & $8.60 \pm 2.95$ & $7.60 \pm 2.13$ & $8.10 \pm 2.58$ \\
\hline Period of LBP (month), mean \pm SD & $10.73 \pm 6.18$ & $10.53 \pm 4.60$ & $10.63 \pm 5.35$ \\
\hline Disability index score, mean \pm SD & $4.20 \pm 1.82$ & $4.80 \pm 1.82$ & $4.50 \pm 1.81$ \\
\hline Pain scale $24 \mathrm{~h}$ (score), mean $\pm \mathrm{SD}$ & $4.27 \pm 1.33$ & $4.47 \pm 1.36$ & $4.37 \pm 1.33$ \\
\hline
\end{tabular}

\subsection{Pain Intensity at Rest and Functional Disability}

The results showed a significant reduction in pain intensity (mean difference: $2.14 \pm 1.50$ (95\% CI: 1.57 to 2.69$)$ at $p<0.001)$ and functional disability (mean difference: $2.33 \pm 1.81$ (95\% CI: 1.66 to 3.01) at $p<0.001)$ between baseline and the 5-week CSE with the ADIM, as shown in Figures 4 and 5, respectively.

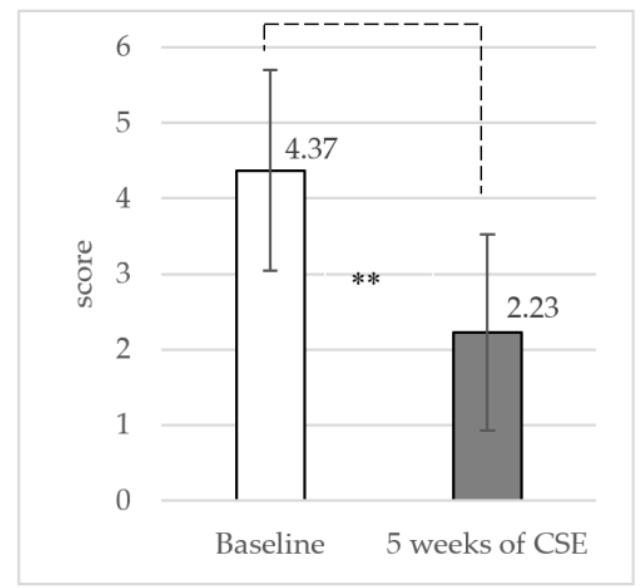

Figure 4. Mean and standard deviation (SD) of pain intensity from baseline to 5 weeks of CSE $(* *<0.001)$. 


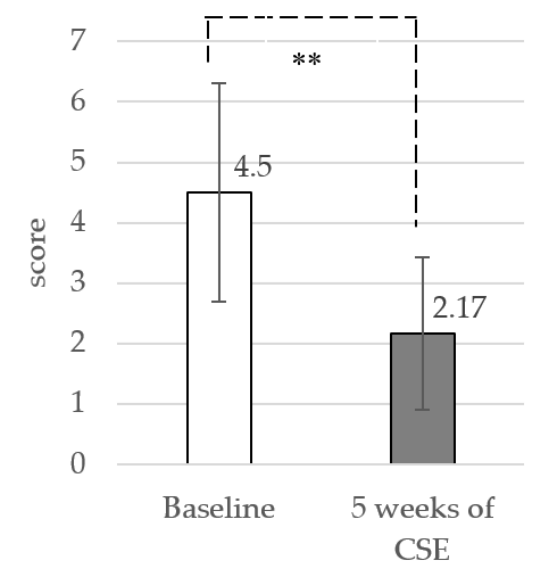

Figure 5. Mean and standard deviation (SD) of functional disability from baseline to 5 weeks of CSE $\left({ }^{* *} p<0.001\right)$.

\subsection{Stature Changes during Sitting}

The stature changes during sitting before and after CSE are shown in Table 2. The result of stature change after sitting for $10 \mathrm{~min}\left(\mathrm{~T}_{\mathrm{sit}}\right)$ showed no significant differences between baseline and after the 5-week CSE with the ADIM technique $(p=0.458)$. This result indicates that $\mathrm{T}_{\text {sit }}$ between baseline and after the 5-week CSE with the ADIM technique was comparable and could be used as a reference point for the stature changes calculation at $\mathrm{T}_{1}, \mathrm{~T}_{2}$, and $\mathrm{T}_{3}$.

Table 2. The stature change during sitting before and after CSE with ADIM.

\begin{tabular}{|c|c|c|c|c|}
\hline & \multirow{2}{*}{$\begin{array}{c}\mathrm{T}_{\text {sit }}(\mathrm{mm}) \\
\text { Mean } \pm \mathrm{SD} \\
(95 \% \mathrm{CI})\end{array}$} & \multicolumn{3}{|c|}{$\begin{array}{c}\text { Mean Change from } \mathrm{T}_{\text {sit }}(\mathrm{mm}) \\
\text { Mean } \pm \operatorname{SD}(95 \% \mathrm{CI})\end{array}$} \\
\hline & & $\mathrm{T}_{1}$ & $T_{2}$ & $T_{3}$ \\
\hline Baseline & $\begin{array}{c}-4.266 \pm 2.221 \\
(-5.095 \text { to } \\
-3.437)\end{array}$ & $\begin{array}{c}-3.999 \pm 1.482 \\
(-4.553 \text { to } \\
-3.446) \mathrm{g}^{*} \mathrm{~h}^{* *}\end{array}$ & $\begin{array}{c}-5.782 \pm 1.605 \\
(-6.382 \text { to } \\
-5.183)^{f^{*} h^{*}}\end{array}$ & $\begin{array}{c}-7.365 \pm 2.180 \\
(-8.179 \text { to } \\
-6.552)^{\mathrm{f}^{* *} \mathrm{~g}^{*}}\end{array}$ \\
\hline $\begin{array}{c}\text { After } 5 \text { weeks of } \\
\text { CSE with ADIM } \\
\text { technique }\end{array}$ & $\begin{array}{c}-3.864 \pm 1.986 \\
(-4.605 \text { to } \\
-3.122)\end{array}$ & $\begin{array}{c}-2.538 \pm 1.004 \\
(-2.913 \text { to } \\
-2.163)^{*} \mathrm{~g}^{* *}\end{array}$ & $\begin{array}{c}-4.027 \pm 1.306 \\
(-4.515 \text { to } \\
-3.539)^{f^{* *} h^{*}}\end{array}$ & $\begin{array}{c}-5.367 \pm 1.258 \\
(-5.837 \text { to } \\
-4.897)^{\mathrm{f}^{* *} \mathrm{~g}^{*}}\end{array}$ \\
\hline $\begin{array}{l}p \text {-value } \\
\text { Between }\end{array}$ & 0.458 & 0.001 & 0.001 & 0.001 \\
\hline
\end{tabular}

Note: Data presented as Mean \pm standard deviation (SD), $\mathrm{T}_{\text {sit }}=$ after sitting for $10 \mathrm{~min}, \mathrm{~T}_{1}=13$ th-15th min $\mathrm{T}_{2}=26$ th-28th $\mathrm{min}, \mathrm{T}_{3}=39$ th-41st $\mathrm{min}, \mathrm{f}=$ significant difference from $\mathrm{T}_{1}, \mathrm{~g}=$ significant difference from $\mathrm{T}_{2}, \mathrm{~h}=$ significant difference from $\mathrm{T}_{3}\left({ }^{*}\right.$ significant difference at $p$-value $<0.008,{ }^{* *}$ significant difference at $p$-value $<0.001)$

At baseline, the results of the current study illustrated that the baseline showed a significant reduction in stature due to time $\left(\mathrm{T}_{1}, \mathrm{~T}_{2}\right.$, and $\left.\mathrm{T}_{3}\right)(p<0.017)$. In the same pattern, the results illustrated that after the 5-week CSE with the ADIM technique, there was a significant reduction in stature due to time.

Comparing baseline and the 5-week CSE with the ADIM technique, the stature changes at $\mathrm{T}_{1}, \mathrm{~T}_{2}$, and $\mathrm{T}_{3}$ were significantly improved in the 5-week CSE with the ADIM technique (Table 2).

\subsection{Pain Intensity during Sitting}

At baseline, the pain intensity of $\mathrm{T}_{2}$ and $\mathrm{T}_{3}$ were significantly increased compared to other time of measurements $\left(\mathrm{T}_{\text {sit }}\right.$ and $\left.\mathrm{T}_{1}\right)$. After the 5-week CSE with the ADIM technique, 
the pain intensity of $\mathrm{T}_{2}(p<0.05)$ and $\mathrm{T} 3(p<0.001)$ was significantly increased from $\mathrm{T}_{\text {sit }}$. At $T_{3}$, pain intensity was significantly increased from $T_{1}$ and $T_{2}(p<0.05)$.

Comparing baseline and the 5-week CSE with the ADIM technique, the pain intensity at $\mathrm{T}_{1}, \mathrm{~T}_{2}$, and $\mathrm{T}_{3}$ was significantly decreased in the 5 -week CSE with the ADIM technique, as shown in Table 3.

Table 3. Comparisons pain intensity during sitting before and after received CSE with ADIM.

\begin{tabular}{|c|c|c|c|c|c|}
\hline \multirow{2}{*}{ Conditions } & \multicolumn{4}{|c|}{ Times } & \multirow{2}{*}{$\begin{array}{c}p \text {-Value } \\
\text { within } \\
\text { Conditions }\end{array}$} \\
\hline & $T_{\text {sit }}$ & $\left(T_{1}\right)$ & $\left(T_{2}\right)$ & $\left(T_{3}\right)$ & \\
\hline Baseline & $\begin{array}{c}3.00 \\
(2.00-5.00) \\
f * g * h * * *\end{array}$ & $\begin{array}{c}3.00 \\
(3.00-5.00) \\
e * g * h *\end{array}$ & $\begin{array}{c}3.50 \\
(3.00-6.00) \\
\mathrm{e} * * \mathrm{f} *\end{array}$ & $\begin{array}{c}3.50 \\
(3.00-6.00) \\
\text { e**f* }\end{array}$ & 0.001 \\
\hline $\begin{array}{c}\text { After } 5 \text { weeks } \\
\text { of CSE with } \\
\text { ADIM } \\
\text { technique }\end{array}$ & $\begin{array}{c}1.00 \\
\underset{\mathrm{g} * \mathrm{~h} * *}{0.00-2.00)}\end{array}$ & $\begin{array}{c}1.00 \\
(0.00-2.25) \\
g * h *\end{array}$ & $\begin{array}{c}1.50 \\
(0.00-3.00) \\
\mathrm{e} * \mathrm{~h} *\end{array}$ & $\begin{array}{c}2.00 \\
(0.00-3.00) \\
e_{* * f * g *}\end{array}$ & 0.001 \\
\hline $\begin{array}{l}p \text {-value } \\
\text { Between }\end{array}$ & 0.632 & 0.001 & 0.001 & 0.001 & \\
\hline
\end{tabular}

Note: Data presented as Median (interquartile range), $p$-value from the Friedman test, ${ }^{* *}$ significant difference at $p$-value $<0.001,{ }^{*}$ significant difference at $p$-value $<0.05$ by the Wilcoxon signed-rank test), $\mathrm{T}_{\text {sit }}=$ after sitting for $10 \mathrm{~min}, \mathrm{~T}_{1}=13$ th -15 th $\mathrm{min}, \mathrm{T}_{2}=26$ th -28 th $\mathrm{min}, \mathrm{T}_{3}=39$ th -41 st min, $\mathrm{e}=$ significant difference from $\mathrm{T}_{\text {sit }}$, $\mathrm{f}=$ significant difference from $\mathrm{T}_{1}, \mathrm{~g}=$ significant difference from $\mathrm{T}_{2}, \mathrm{~h}=$ significant difference from $\mathrm{T}_{3}$.

\subsection{Trunk Muscle Fatigue during the Experiment}

At baseline, the MDF in the sitting condition is shown in Table 4. The Friedman test revealed a significant difference in the MDF values in the muscles and both sides at each time of measurement during prolonged sitting. The Wilcoxon signed-rank tests showed a significant difference between the measurement times. For both sides of the $\operatorname{Tr} \mathrm{A}$ and IO muscles, the MDF value at the 15th-25th min was significantly decreased compared to that of the $0-10$ th $\mathrm{min}$. A further reduction in the MDF value was observed at the 28 th-38th $\mathrm{min}$.

Table 4. Comparison muscle fatigue between before and after performed CSM with ADIM exercise during prolong sitting.

\begin{tabular}{|c|c|c|c|c|c|c|}
\hline \multirow[b]{2}{*}{$\begin{array}{l}\text { Muscle Fatigue } \\
\text { (Hz.) }\end{array}$} & \multicolumn{2}{|c|}{ Right } & \multirow[b]{2}{*}{$p$-Value } & \multicolumn{2}{|c|}{ Left } & \multirow[b]{2}{*}{$p$-Value } \\
\hline & $\begin{array}{c}\text { Baseline } \\
\text { Median } \\
\text { (Interquartile Range) }\end{array}$ & $\begin{array}{c}\text { After } 5 \text { Weeks of CSE } \\
\text { Median } \\
\text { (Interquartile Range) }\end{array}$ & & $\begin{array}{c}\text { Baseline } \\
\text { Median } \\
\text { (Interquartile Range) }\end{array}$ & $\begin{array}{c}\text { After } 5 \text { Weeks of CSE } \\
\text { Median } \\
\text { (Interquartile Range) }\end{array}$ & \\
\hline $\begin{array}{l}\text { RA } \\
\text { (0-10th min) } \\
\text { (15th-25th min) } \\
\text { (28th-38th min) } \\
\text { p-value }\end{array}$ & $\begin{array}{c}25.71(24.99-27.25) \\
25.70(917.29-27.64) \\
25.72(25.70-28.69) \\
0.177\end{array}$ & $\begin{array}{l}25.70(25.69-25.71) \\
25.70(23.91-25.71) \\
25.71(25.69-25.72) \\
0.441\end{array}$ & $\begin{array}{l}0.713 \\
0.992 \\
0.144\end{array}$ & $\begin{array}{l}25.71(15.72-28.95) \\
25.71(16.95-27.34) \\
25.71(25.69-28.70) \\
0.852\end{array}$ & $\begin{array}{l}25.70(25.12-25.71) \\
25.71(25.69-25.72) \\
25.70(24.72-25.71) \\
0.084\end{array}$ & $\begin{array}{l}0.128 \\
0.926 \\
0.130\end{array}$ \\
\hline $\begin{array}{l}\text { TrA \& IO } \\
(0-10 \text { th } \min ) \\
\text { (15th-25th } \mathrm{min}) \\
\text { (28th-38th } \mathrm{min}) \\
p \text {-value }\end{array}$ & $\begin{array}{c}42.59(34.58-42.72) \\
\mathrm{b}^{*} \mathrm{c}^{*} \\
35.99(35.69-37.99) \mathrm{a}^{*} \\
35.71(33.21-36.45) \mathrm{a}^{*} \\
0.001\end{array}$ & $\begin{array}{c}46.71(46.63-48.32) \\
45.30(40.80-47.96) \\
45.70(41.99-48.71) \\
0.058\end{array}$ & $\begin{array}{l}0.001^{* *} \\
0.001^{* *} \\
0.001^{* *}\end{array}$ & $\begin{array}{c}42.70(35.37-42.73) \\
\mathrm{b}^{*} \mathrm{c}^{*} \\
36.15(34.19-37.32) \mathrm{a}^{*} \\
35.95(33.53-37.21) \mathrm{a}^{*} \\
0.001^{*}\end{array}$ & $\begin{array}{c}46.71(44.88-48.69) \\
45.45(41.49-47.23) \\
45.99(43.45-48.65) \\
0.503\end{array}$ & $\begin{array}{l}0.001^{* *} \\
0.001^{* *} \\
0.001 * *\end{array}$ \\
\hline $\begin{array}{l}\text { ICLT } \\
(0-10 \text { th } \min ) \\
(15 \text { th-25th } \min ) \\
\text { (28th-38th } \min ) \\
\text {-value }\end{array}$ & $\begin{array}{c}35.70(33.21-36.03) \\
35.69(33.28-35.72) \\
35.70(33.85-35.71) \\
0.873\end{array}$ & $\begin{array}{c}36.14(35.69-37.94) \\
35.72(35.30-37.33) \\
36.70(33.85-35.71) \\
0.644\end{array}$ & $\begin{array}{l}0.060 \\
0.206 \\
0.153\end{array}$ & $\begin{array}{c}35.70(34.81-35.72) \\
35.69(33.66-36.21) \\
35.69(33.58-35.71) \\
0.721\end{array}$ & $\begin{array}{c}35.71(34.39-37.76) \\
35.71(35.66-36.47) \\
35.71(35.69-37.05) \\
0.594\end{array}$ & $\begin{array}{l}0.524 \\
0.289 \\
0.360\end{array}$ \\
\hline
\end{tabular}


Table 4. Cont.

\begin{tabular}{|c|c|c|c|c|c|c|}
\hline \multirow[b]{2}{*}{$\begin{array}{l}\text { Muscle Fatigue } \\
\text { (Hz.) }\end{array}$} & \multicolumn{2}{|c|}{ Right } & \multirow[b]{2}{*}{$p$-Value } & \multicolumn{2}{|c|}{ Left } & \multirow[b]{2}{*}{$p$-Value } \\
\hline & $\begin{array}{c}\text { Baseline } \\
\text { Median } \\
\text { (Interquartile Range) }\end{array}$ & $\begin{array}{c}\text { After } 5 \text { Weeks of CSE } \\
\text { Median } \\
\text { (Interquartile Range) }\end{array}$ & & $\begin{array}{c}\text { Baseline } \\
\text { Median } \\
\text { (Interquartile Range) }\end{array}$ & $\begin{array}{c}\text { After } 5 \text { Weeks of CSE } \\
\text { Median } \\
\text { (Interquartile Range) }\end{array}$ & \\
\hline \multicolumn{7}{|l|}{ LM } \\
\hline (0-10th $\min )$ & $49.04(46.42-52.79)$ & $52.65(47.71-53.57)$ & 0.185 & $49.36(45.71-52.38)$ & $51.90(48.22-53.57)$ & 0.175 \\
\hline (15th-25th $\min$ ) & $49.41(46.96-53.57)$ & $52.74(48.71-53.57)$ & 0.098 & $49.21(47.71-55.70)$ & $52.33(48.15-55.40)$ & 0.544 \\
\hline (28th-38th $\min$ ) & $49.21(47.71-55.69)$ & $52.34(48.72-55.72)$ & 0.082 & $49.84(48.00-55.69)$ & $52.42(48.68-55.71)$ & 0.237 \\
\hline$p$-value & 0.695 & 0.341 & & 0.273 & 0.125 & \\
\hline
\end{tabular}

Note: Data presented as Median (interquartile range). Significant difference at ${ }^{*} p$-value $<0.05,{ }^{* *} p$-value $<0.001$ by Wilcoxon signed-rank test. $\mathrm{a}=$ significant difference from $0-10$ th, $\mathrm{b}=$ significant difference from 15 th-25th $\mathrm{c}=$ significant difference from 28th-38th.

After the 5-week CSE with the ADIM technique, the Friedman test did not reveal a significant difference in the MDF value in trunk muscles and both sides at all times of measurement. Compared with baseline values, the 5-week CSE with the ADIM technique showed a significant improvement in the MDF values (both sides of TrA and IO, the MDF value of 15 th-25th and 28 th-38th $\mathrm{min}$ ).

\section{Discussion}

The aim of this study was to investigate differences in stature change, pain, and trunk muscle fatigue during prolonged sitting conditions in sedentary workers with CLBP between baseline and the 1st day after the 5-week CSE with the ADIM technique.

The results of the current study showed that the 5-week CSE with the ADIM technique provided a significant decrease in resting pain (mean difference: $2.14 \pm 1.50 ; p<0.001$ ) and improvement in functional disability (mean difference: $2.33 \pm 1.81 ; p<0.001$ ). The result of the current study agreed with those of previous studies that reported the potential of CSE to improve functional disability in patients with CLBP [47-49]. The results of the current study demonstrated that the CSE program might be clinically advantageous for CLBP patients with functional disability improvement by reducing pain.

During prolonged sitting, forces from bodyweight cause deformation of the elastic components of the disc and increased intra-discal pressure [50,51]. Fluid loss is known to occur when the pressure inside the disc increases and can be indicated as the major mechanism to account for the reduction in disc height and consequent stature loss $[52,53]$. Prolonged sitting in CLBP participants induced stature loss (mean difference $-7.365 \mathrm{~mm}$ ) at $41 \mathrm{~min}\left(\mathrm{~T}_{3}\right)$ (Table 2).

The current study revealed that bilateral TrA and IO muscle fatigue occurred earlier during sitting (approximately 15-25 min after sitting) (Table 3). Sitting for prolonged periods has been partly attributed to trunk muscle fatigue resulting from the continuous contraction of deep trunk muscles in seated postures $[9,10]$. During prolonged sitting, the lumbar multifidus is passively stretched, resulting in increased co-contraction of the $\operatorname{Tr} \mathrm{A}$ and IO muscles to balance the back muscle forces. Consequently, the TrA and IO muscles become fatigued over time $[9,10]$.

A significant increase in low back pain in the sitting condition was found in this study, suggesting that static loading of the lumbar spine during prolonged sitting may be associated with disc compression [54,55]. Healey et al. (2005) and Rodacki et al. (2003) proposed that persistent contraction of the superficial paraspinal muscles in patients with CLBP may produce greater compressive loading, increasing disc compression and reducing stature [25,27]. Moreover, the results of the current study demonstrate that the sitting condition reduced deep trunk muscle activation. These results may explain increased low back pain $[14,56]$. The results of the present study align with previous studies showing that perceived body discomfort increased significantly during prolonged sitting [56].

After the 5-week CSE with the ADIM technique, participants showed significantly improved stature changes during prolonged sitting. The stature change at the $\mathrm{T}_{1}$ (mean difference: $1.462 \pm 1.752 \mathrm{~mm} ; p<0.001$ ), $\mathrm{T}_{2}$ (mean difference: $1.756 \pm 1.752 \mathrm{~mm} ; p<0.001$ ), 
and $\mathrm{T}_{3}$ occasion (mean difference: $1.998 \pm 2.653 \mathrm{~mm} ; p<0.001$ ) was significantly improved before and after the 5-week CSE with the ADIM technique. Although our mean difference in stature change was only $1.99 \mathrm{~mm}$, which did not reach the minimal clinically important stature change of $3 \mathrm{~mm}$ [12], there is evidence that changes in stature of a magnitude above $0.985 \mathrm{~mm}$ can be attributed to intervention effects in CLBP participants [57].

Thus, we show that the 5-week CSE with the ADIM technique can enhance recovery of disc height and reduce the loading on other spinal structures, which may facilitate a reduction in symptoms in patients with low back pain during prolonged sitting. This is consistent with the findings of Healey et al. (2005) and Lewis et al. (2014). They reported significant positive correlations between delayed stature recovery and higher levels of pain and disability $[27,32]$.

Our results demonstrated that the 5-week CSE could improve trunk muscle endurance during prolonged sitting when compared with baseline. The results showed that both sides of TrA and IO significantly improved the MDF (at 0-10, 15-25th, and 28-38th min) when compared with baseline values. These revealed that muscle endurance increased after the 5-week CSE with the ADIM technique, which could be related to the specific effects of CSE with the ADIM technique on deep muscle activities. Macdonald et al. (2006) indicated that deep trunk muscles have a high percentage of type I muscle fibers, blood vessels, and mitochondria [58]. Therefore, CSE with the ADIM technique can improve the endurance of deep trunk muscles during prolonged sitting. Increased activity of the deep trunk muscle is thought to raise intra-abdominal pressure [59], resulting in decreased spinal loading $[60,61]$. This suggests that the CSE with the ADIM technique can increase deep trunk muscle activity in CLBP participants by reducing compression forces on the spine during prolonged sitting [8], leading to improved stature recovery.

The results of the five weeks of CSE with the ADIM technique significantly improved low back pain at all measurement time points $\left(\mathrm{T}_{1}, \mathrm{~T}_{2}\right.$, and $\left.\mathrm{T}_{3}\right)$ when compared with the baseline. However, the participants reported significantly increased pain intensity throughout the increased sitting time. Static loading of the lumbar spine increases stress in spinal structures [54,55]. These results may increase low back pain [14,56]. Thus, in addition to performing CSE with the ADIM technique, participants should perform the movement during the working day to prevent lower back pain during prolonged sitting.

The current study has some limitations. First, the investigation was conducted in a laboratory; the findings of this study may have limited ecological validity, and a real-life situation may be required in future investigations. Second, the participants were young, with a small age range (aged 21-29 years). Thus, the results might not be applicable to other age groups due to the variation in degenerative stage. Third, the current study was limited to the immediate effects of the 5-week CSE with the ADIM technique. Future studies should investigate the long-term follow-up effects of this program. Fourth, although the participants in this study reported a significant increase in low back pain during prolonged sitting, a history of previous injury did not meet our exclusion criteria. Therefore, low back pain may be due to other reasons besides prolonged sitting. Adding a history of previous injury in the exclusion criteria may better clarify the cause of low back pain in future studies. Lastly, the current study included only one group that performed the preand post-exercise interventions. Future investigations should include a control group or a comparison of CSE with other exercises to strengthen the findings.

\section{Conclusions}

This study demonstrated that a 5-week CSE with the ADIM technique affects the pain at rest and functional disability in sedentary workers with CLBP. Our result showed that CSE with the ADIM technique provides a protective effect on detrimental reductions in stature change and trunk muscle fatigue during prolonged sitting in young participants under controlled conditions in a laboratory. Based on these findings, we recommend that CLBP patients (aged 21-29 years) should perform CSE with the ADIM technique at home to reduce low back pain problems due to prolonged sitting activities. 
Author Contributions: P.S.: conceptualization, data curation, formal analysis, methodology, writing, and editing; R.P.: conceptualization, data curation, funding acquisition, project administration, resources, writing, and editing; T.C.: data analysis, reviewing, and editing. All authors have read and agreed to the published version of the manuscript.

Funding: This research received no external funding.

Institutional Review Board Statement: The study was conducted according to the guidelines of the Declaration of Helsinki and approved by the Ethics Committee of Center for Ethics in Human Research, Khon Kaen University (no. HE612220).

Informed Consent Statement: Informed consent was obtained from all subjects involved in the study.

Data Availability Statement: The data will be available for anyone who wishes to access them for any purpose and contract should be made via the corresponding author (rungthiprt@gmail.com).

Acknowledgments: The authors thank the participants for their willingness to participate in this study. This work was supported by the Royal Golden Jubilee (RGJ) Ph.D. Programme, the Thailand Research Fund (TRF), Thailand (PHD/0090/2558) and the Research Center in Back, Neck, Other Joint Pain and Human Performance (BNOJPH), Khon Kaen University, Thailand. Many thanks to Rose Boucaut, School of Health Sciences (Physiotherapy), University of South Australia, for English editing.

Conflicts of Interest: The authors declare no conflict of interest.

\section{Appendix A}

Table A1. Program of the CSE with ADIM technique.

Week $\quad$ Exercise Protocol
The participants were given the instructions on how to isolate activation of the TrA muscles correctly. After that, they
were asked to draw their lower abdomen gently in towards the spine (ADIM) with normal breathing control, and no
movement of the spine and pelvis while in a prone lying position on a couch with a small pillow placed beneath their
ankles. In addition, a pressure biofeedback device set at $70 \mathrm{mmHg}$ was placed under the lower abdomen of the
participants. If they were able to lower pressure 4 to $10 \mathrm{mmHg}$, it represented successful activation of the transversus
abdominis muscle. The exercises progressed until the participants could perform muscle contractions for $10 \mathrm{~s}$ holds
with 10 repetitions/set 10 sets/day.
The participants performed co-contraction of the TrA and LM muscles while in a crooked lying position with both hips
at 45 degrees and both knees at 90 degrees. They were asked to perform the ADIM technique with floor muscles,
normal breathing control, and no movement of the spine and pelvis. Furthermore, they used their index and middle
fingers to palpate contraction of the TrA muscle and opposite 2 fingers palpated contraction of LM muscle. If the
participants performed correctly, they could feel the tight contraction of each muscle under their fingers. The exercises
progressed until the participants could perform muscle contractions for $10 \mathrm{~s}$ holds with 10 repetitions / set 10 sets/day.


Table A1. Cont.

\begin{tabular}{ll}
\hline Week & Exercise Protocol \\
& The participants performed co-contraction of the TrA and LM muscles while sitting on a chair. They were asked to \\
perform the ADIM technique with normal breathing control, and no movement of the spine and pelvis. Furthermore, \\
they used their index and middle fingers to palpate contraction of the TrA muscle and opposite 2 fingers palpated \\
contraction of the LM muscle. If the participants performed correctly, they could feel the tight contraction of each \\
muscle under their fingers. The exercises progressed until the participants could perform muscle contractions for $10 \mathrm{~s}$ \\
holds with 10 repetitions/set 10 sets/day. The next exercise in this week was to train co-contraction of these muscles \\
with the trunk forward and backward while sitting on a chair and keeping their lumbar spine and pelvis in a neutral \\
position. The second exercise in this week required $10 \mathrm{~s}$ holds with 10 repetitions / set 10 sets/day. \\
The participants performed co-contraction of the TrA and LM muscles during sitting on a balance board. They were \\
asked to perform co-contraction of the muscles with the trunk forward and backward while sitting on a balance board \\
and keeping their lumbar spine and pelvis in a neutral position. They performed each pose for $10 \mathrm{~s}$ holds with \\
10 repetitions/set 10 sets/day.
\end{tabular}

\section{References}

1. Sedentary Behaviour Research Network. Letter to the editor: Standardized use of the terms "sedentary" and "sedentary behaviours". Appl. Physiol. Nutr. Metab. 2012, 37, 540-542. [CrossRef] [PubMed]

2. Hadgraft, N.T.; Lynch, B.M.; Clark, B.K.; Healy, G.N.; Owen, N.; Dunstan, D.W. Excessive sitting at work and at home: Correlates of occupational sitting and TV viewing time in working adults. BMC Public Health 2015, 15, 899. [CrossRef]

3. Saidj, M.; Menai, M.; Charreire, H.; Weber, C.; Enaux, C.; Aadahl, M.; Kesse-Guyot, E.; Hercberg, S.; Simon, C.; Oppert, J.M. Descriptive study of sedentary behaviours in 35,444 French working adults: Cross-sectional findings from the ACTI-Cités study. BMC Public Health 2015, 15, 379. [CrossRef] [PubMed]

4. Montakarn, C.; Nuttika, N. Physical activity levels and prevalence of low back pain in Thai call-center operators. Indian J. Occup. Environ. Med. 2016, 20, 125-128. [CrossRef] [PubMed]

5. Balagué, F.; Mannion, A.F.; Pellisé, F.; Cedraschi, C. Non-specific low back pain. Lancet 2012, 379, 482-491. [CrossRef]

6. Jiménez, R.; Bennett, P.; García, O.; Vargas, C. Fatigue detection during sit-to-stand test based on surface electromyography and acceleration: A case study. Sensors 2019, 19, 4202. [CrossRef]

7. Olafsson, G.; Jonsson, E.; Fritzell, P.; Hägg, O.; Borgström, F. A health economic lifetime treatment pathway model for low back pain in Sweden. J. Med. Econ. 2017, 20, 1281-1289. [CrossRef] [PubMed]

8. Saiklang, P.; Puntumetakul, R.; Selfe, J.; Yeowell, G. An Evaluation of an Innovative Exercise to Relieve Chronic Low Back Pain in Sedentary Workers. Available online: https:/ / pubmed.ncbi.nlm.nih.gov/33111563/ (accessed on 22 December 2021).

9. Waongenngarm, P.; Rajaratnam, B.S.; Janwantanakul, P. Internal oblique and transversus abdominis muscle fatigue induced by slumped sitting posture after $1 \mathrm{~h}$ of sitting in office workers. Saf. Health Work 2016, 7, 49-54. [CrossRef] [PubMed]

10. Areeudomwong, P.; Puntumetakul, R.; Kaber, D.B.; Wanpen, S.; Leelayuwat, N.; Chatchawan, U. Effects of handicraft sitting postures on lower trunk muscle fatigue. Ergonomics 2012, 55, 693-703. [CrossRef]

11. Lewis, S.E.; Fowler, N.E. Changes in intervertebral disk dimensions after a loading task and the relationship with stature change measurements. Arch. Phys. Med. Rehabil. 2009, 90, 1795-1799. [CrossRef]

12. Kanlayanaphotporn, R.; Trott, P.; Williams, M.; Fulton, I. Effects of chronic low back pain, age and gender on vertical spinal creep. Ergonomics 2003, 46, 561-573. [CrossRef]

13. Watanabe, S.; Kobara, K.; Yoshimura, Y.; Osaka, H.; Ishida, H. Influence of trunk muscle co-contraction on spinal curvature during sitting. J. Back Musculoskelet Rehabil. 2014, 27, 55-61. [CrossRef] [PubMed]

14. Fryer, J.C.J.; Quon, J.A.; Smith, F.W. Magnetic resonance imaging and stadiometric assessment of the lumbar discs after sitting and chair-care decompression exercise: A pilot study. Spine J. 2010, 10, 297-305. [CrossRef]

15. Saiklang, P.; Puntumetakul, R.; Swangnetr, M.; Boucaut, R. The immediate effect of the abdominal drawing-in maneuver technique on stature change in seated sedentary workers with chronic low back pain. Ergonomics 2020, 64, 55-68. [CrossRef]

16. Holmes, M.W.R.; De Carvalho, D.E.; Karakolis, T.; Callaghan, J.P. Evaluating abdominal and lower back muscle activity while performing core exercises on a stability ball and a dynamic office chair. Hum. Factors 2015, 57, 1149-1161. [CrossRef] [PubMed]

17. Gregory, D.E.; Dunk, M.N.; Callaghan, J.P. Stability ball versus office chair: Comparisonof muscle activation and lumbar spine posture during prolonged sitting. Hum. Factors 2006, 48, 142-153. [CrossRef]

18. Panjabi, M.M. Clinical spinal instability and low back pain. J. Electromyogr. Kinesiol. J. Electromyogr. Kines 2003, 13, 371-379. [CrossRef]

19. Bergmark, A. Stability of the lumbar spine: A study in mechanical engineering. Acta Orthop. Scand Suppl. 1989, 230, 1-54. [CrossRef]

20. Faries, M.D.; Greenwood, M. Core Training: Stabilizing the confusion. Strength Cond J. 2007, 29, 10-25. [CrossRef]

21. Kavcic, N.; Grenier, S.; McGill, S.M. Determining the stabilizing role of individual torso muscles during rehabilitation exercises. Spine 2004, 29, 1254-1265. [CrossRef] [PubMed] 
22. Marshell, P.W.; Murphy, B.A. Delayed abdominal muscle onsets and self-report measures of pain and disability in chronic low back pain. J. Electromyogr. Kinesiol. 2010, 20, 833-839. [CrossRef]

23. Silfies, S.P.; Mehta, R.; Smith, S.S.; Karduna, A.R. Differences in feedforward trunk muscle activity in subgroups of patients with mechanical low back pain. Arch. Phys. Med. Rehabil. 2009, 90, 1159-1169. [CrossRef]

24. Tsao, H.; Druitt, T.R.; Schollum, T.M.; Hodges, P.W. Motor training of the lumbar paraspinal muscles induces immediate changes in motor coordination in patients with recurrent low back pain. J. Pain 2010, 11, 1120-1128. [CrossRef]

25. Rodacki, C.L.; Fowler, N.E.; Rodacki, A.L.; Birch, K. Stature loss and recovery in pregnant women with and without low back pain. Arch. Phys. Med. Rehabil. 2003, 84, 507-512. [CrossRef]

26. Singh, R.E.; Iqbal, K.; White, G.; Hutchinson, T.E. A Systematic Review on Muscle Synergies: From Building Blocks of Motor Behavior to a Neurorehabilitation Tool. Appl. Bionics. Biomech. 2018, 22, 3165368. [CrossRef]

27. Healey, E.L.; Fowler, N.E.; Burden, A.M.; McEwan, I.M. The influence of different unloading positions upon stature recovery and paraspinal muscle activity. Clin. Biomech. Bristol. Avon. 2005, 20, 365-371. [CrossRef] [PubMed]

28. Puntumetakul, R.; Areeudomwong, P.; Emasithi, A.; Yamauchi, J. Effect of 10-week core stabilization exercise training and detraining on pain-related outcomes in patients with clinical lumbar instability. Patient Prefer. Adherence 2013, 7, 1189-1199. [CrossRef] [PubMed]

29. Puntumetakul, R.; Saiklang, P.; Tapanya, W.; Chatprem, T.; Kanpittaya, J.; Arayawichanon, P.; Boucaut, R. The effects of core stabilization exercise with the abdominal drawing-in maneuver technique versus general strengthening exercise on lumbar segmental motion in patients with clinical lumbar instability: A randomized controlled trial with 12-month follow-up. Int. J. Environ. Res. Public Health 2021, 18, 7811. [CrossRef] [PubMed]

30. Areeudomwong, P.; Puntumetakul, R.; Jirarattanaphochai, K.; Wanpen, S.; Kanpittaya, J.; Chatchawan, U.; Yamauchi, J. Core stabilization exercise improves pain intensity, functional disability and trunk muscle activity of patients with clinical lumbar instability: A pilot randomized controlled study. J. Phys. Ther. Sci. 2012, 24, 1007-1012. [CrossRef]

31. Boonstra, M.A.; Stewart, R.E.; Köke, A.J.A.; Oosterwijk, R.F.A.; Swaan, J.L.; Schreurs, K.M.G.; Schiphorst, H.R. Cut-off points for mild, moderate, and severe pain on the numeric rating scale for pain in patients with chronic musculoskeletal pain: Variability and influence of sex and catastrophizing. Front. Psychol. 2016, 7, 1466. [CrossRef] [PubMed]

32. Lewis, S.; Holmes, P.; Woby, S.; Hindle, J.; Fowler, N. Changes in muscle activity and stature recovery after active rehabilitation for chronic low back pain. Man. Ther. 2014, 19, 178-183. [CrossRef] [PubMed]

33. Hall, M.A.; Maher, C.G.; Latimer, J.; Ferreira, M.L.; Costa, L.O.P. The patient-specific functional scale is more responsive than the roland morris disability questionnaire when activity limitation is low. Eur. Spine J. 2011, 20, 79-86. [CrossRef] [PubMed]

34. Phimphasak, C.; Swangnetr, M.; Puntumetakul, R.; Chatchawan, U.; Boucaut, R. Effects of seated lumbar extension postures on spinal height and lumbar range of motion during prolonged sitting. Ergonomics 2016, 59, 112-120. [CrossRef]

35. Rodacki, C.L.; Fowler, N.E.; Rodacki, A.L.; Birch, K. Technical note: Repeatability of measurement in determining stature in sitting and standing postures. Ergonomics 2001, 44, 1076-1085. [CrossRef]

36. Imai, A.; Kaneoka, K.; Okubo, Y.; Shiina, I.; Tatsumura, M.; Izumi, S. Trunk muscle activity during lumbar stabilization exercises on both a stable and unstable surface. J. Orthop. Sports Phys. Ther. 2010, 40, 369-375. [CrossRef]

37. Marshall, P.; Murphy, B. The validity and reliability of surface EMG to assess the neuromuscular response of the abdominal muscles to rapid limb movement. J. Electromyogr. Kinesiol. 2003, 13, 477-489. [CrossRef]

38. Danneels, L.A.; Cagnie, B.J.; Cools, A.M.; Vanderstraeten, G.G.; Cambier, D.C.; Witvrouw, E.E. Intra-operator and inter-operator reliability of surface electromyography in the clinical evaluation of back muscles. Man. Ther. 2001, 6, 145-153. [CrossRef]

39. Ostelo, R.W.J.G.; de Vet, J.C.W. Clinically important outcomes in low back pain. Best Res. Clin. Rheumatol. 2005, $19,593-607$. [CrossRef]

40. Roland, M.; Fairbank, J. The roland-morris disability questionnaire and the oswestry disability questionnaire. Spine 2000, 25, 3115-3124. [CrossRef]

41. Jirarattanaphochai, K.; Jung, S.; Sumananont, C.; Saengnipanthkul, S. Reliability of the Roland-Morris Disability Questionnaire (Thai version) for the evaluation of low back pain patients. J. Med. Assoc. Thai. 2005, 88, 407-411. [PubMed]

42. Healey, E.L.; Burden, A.M.; McEwan, I.M.; Fowler, N.E. Stature loss and recovery following a period of loading: Effect of time of day and presence or absence of low back pain. Clin. Biomech. Bristol. Avon. 2008, 23, 721-726. [CrossRef] [PubMed]

43. Puntumetakul, R.; Trott, P.; Williams, M.; Fulton, I. Effect of time of day on the vertical spinal creep response. Appl. Ergon. 2009, 40, 33-38. [CrossRef] [PubMed]

44. Healey, E.L.; Burden, A.M.; McEwan, I.M.; Fowler, N.E. Diurnal variation in stature: Do those with chronic low back pain differ from asymptomatic controls? Clin. Biomech. 2011, 26, 331-336. [CrossRef]

45. Fowler, N.E.; de Lourdes Rodacki, C.; Rodacki, A.L. Spinal shrinkage and recovery in women with and without low back pain. Arch. Phys. Med. Rehabil. 2005, 86, 505-511. [CrossRef] [PubMed]

46. Corlett, E.N.; Eklund, J.A.E.; Reilly, T.; Troup, J.D.G. Assessment of workload from measurements of stature. Appl. Ergon. 1987, 18, 65-71. [CrossRef]

47. Koumantakis, G.A.; Watson, P.J.; Oldham, J.A. Trunk muscle stabilization training plus general exercise versus general exercise only: Randomized controlled trial of patients with recurrent low back pain. Phys. Ther. 2005, 85, 209-225. [CrossRef]

48. Moseley, G.L.; Hodges, P.; Gandevia, S.C. Deep and superficial fibers of the lumbar multifidus muscle are differentially active during voluntary arm movements. Spine 2002, 27, 29-36. [CrossRef] 
49. Goldby, L.; Moore, A.; Trew, M. A randomized controlled trial investigating the efficiency of musculoskeletal physiotherapy on chronic low back disorder. Spine 2006, 31, 1083-1093. [CrossRef]

50. Schmidt, H.; Reitmaier, S.; Graichen, F.; Shirazi-Adl, A. Review of the fluid flow within intervertebral discs-How could in vitro measurements replicate in vivo? J. Biomech. 2016, 49, 3133-3146. [CrossRef]

51. Vergroesen, P.P.A.; Van Der Veen, A.J.; Emanuel, K.S.; Van Dieën, J.H.; Smitm, T.H. The poro-elastic behaviour of the intervertebral disc: A new perspective on diurnal fluid flow. J. Biomech. 2016, 49, 857-863. [CrossRef]

52. Munster, M.M.; Brismée, J.M.; Sizer, P.S.; Browne, K.; Dewan, B.; Litke, A.; Pape, J.L.; Sobczak, S. Can 5 min of repetitive prone press-ups and sustained prone press-ups following a period of spinal loading reverse spinal shrinkage? Physiother Theory Pract. 2018, 35, 1-9. [CrossRef]

53. Pape, J.L.; Brismée, J.M.; Sizer, P.S.; Matthijs, O.C.; Browne, K.L.; Dewan, B.M.; Sobczak, S. Increased spinal height using propped slouched sitting postures: Innovative ways to rehydrate intervertebral discs. Appl. Ergon. 2018, 66, 9-17. [CrossRef] [PubMed]

54. Billy, G.G.; Lemieux, S.K.; Chow, M.X. Changes in lumbar disk morphology associated with prolonged sitting assessed by magnetic resonance imaging. PMER 2014, 6, 790-795. [CrossRef]

55. Fryer, J.; Zhang, W. Preliminary investigation into a seated unloading movement strategy for the lumbar spine: A pilot study. J. Bodyw. Mov. Ther. 2010, 14, 119-126. [CrossRef] [PubMed]

56. Søndergaard, K.H.; Olesen, C.G.; Sondergaard, E.K.; de Zee, M.; Madeleine, P. The variability and complexity of sitting postural control are associated with discomfort. J. Biomech. 2010, 43, 1997-2001. [CrossRef] [PubMed]

57. Saiklang, P.; Puntumetakul, R.; Siritaratiwat, W.; Boucaut, R. Effect of Time of Day on the Magnitude of Stature Change Response Variability in Participants With Chronic Low Back Pain on Consecutive 2 Days. Trends Sci. 2021, 18, 678. [CrossRef]

58. MacDonald, D.A.; Moseley, G.L.; Hodges, P.W. The lumbar multifidus: Does the evidence support clinical beliefs? Man. Ther. 2006, 11, 254-263. [CrossRef]

59. Tayashiki, K.; Takai, Y.; Maeo, S.; Kanehisa, H. Intra-abdominal pressure and trunk muscular activities during abdominal bracing and hollowing. Int. J. Sports Med. 2015, 37, 134-143. [CrossRef]

60. Stokes, I.A.F.; Gardner-Morse, M.G.; Henry, S.M. Intra-abdominal pressure and abdominal wall muscular function: Spinal unloading mechanism. Clin. Biomech. 2010, 25, 859-866. [CrossRef]

61. Rodacki, C.L.; Rodacki, A.; Ugrinowitsch, C.; Zielinski, D.; Costa, R.B. Spinal unloading after abdominal exercises. Clin. Biomech. 2008, 23, 8-14. [CrossRef] [PubMed] 